\title{
HEGEMONIA E OS PROGRAMAS DE EDUCAÇÃO INDÍGENA NO MÉXICO E NO BRASIL $(1940-1970)^{1}$
}

\author{
LÍGIA DUQUE PLATERO² \\ UNAM/México
}

\begin{abstract}
RESUMO: Neste artigo, apresento informações sobre os programas de educação indígena das agências indigenistas do Brasil e do México, entre 1940 e 1970, e realizo uma breve discussão sobre a influência desses programas nos processos de formação de hegemonia dos Estados ampliados entre os povos indígenas desses países no período citado. Nas escolas do Instituto Nacional Indigenista (INI), no México, e, principalmente, do Serviço de Proteção aos Índios (SPI), no Brasil, as escolas enfatizaram o ensino da língua nacional em seus currículos $e$ influenciaram na criação da ideia da existência da nacionalidade mestiça, visando ao desenvolvimento e a integração dos povos indígenas à nação. Em ambos os países, missões religiosas participaram da educação indígena - e, aqui, destaco a atuação do Summer Institute of Linguistics (SIL). No caso do México, destaco dois momentos do indigenismo associados à educação para os indígenas e enfatizo a participação dos promotores culturais bilíngues como intermediários culturais entre as instituições indigenistas e as comunidades. Já no caso do Brasil, os professores e professoras eram não indígenas e sua influência foi mais restrita.
\end{abstract}

PALAVRAS-CHAVE: História dos índios; Política indigenista; Educação escolar indígena; Serviço de Proteção ao Índio; Instituto Nacional Indigenista.

ABSTRACT: In this article, we present information about the programs of indigenous Indian education agencies in Brazil and Mexico between 1940 and 1970, and conduct a brief discussion of the influence of these programs in the processes of the State's hegemony formation amplified among indigenous peoples in these countries in the period cited. In the schools of the National Indigenous Institute (INI) in Mexico, and especially in the Indian Protection Service (SPI) in Brazil, the schools emphasize the teaching of the national language in their curricula and influence the creation of the idea of a mestiza nationality, aiming to develop and integrate indigenous peoples to the nation. In both countries, religious missions attended the indigenous education, and here we highlight the work of the Summer Institute of Linguistics (SIL). In the case of Mexico, I highlight two moments of indigenism associated with indigenous education, and I

\footnotetext{
${ }^{1}$ Este artigo foi publicado em francês com o título L'hegemonie et les programmes d'éducation autochtone au Mexique et au Brésil (1940 - 1970), na revista Recherches Amérindiennes au Québec, XLIV, n. 2-3, 2014. Para esta publicação, recebeu algumas alterações de conteúdo.

${ }^{2}$ Lígia Duque Platero é graduada e licenciada $(2006,2007)$ em História pela Universidade de São Paulo (USP) e mestra (2012) em Estudos Latino-americanos pela Universidade Nacional Autônoma do México (UNAM). Foi orientada pelo etnólogo Dr. Andrés Medina Hernández, do Instituto de Investigações Antropológicas (IIA) da UNAM. Atualmente, faz doutorado em Ciências Humanas, com ênfase em Antropologia, no Programa de Pós-graduação em Sociologia e Antropologia (PPGSA) da Universidade Federal do Rio de Janeiro (UFRJ), onde realiza pesquisa nas áreas de Etnologia e Antropologia urbana, com o projeto Fazer parentes: uma descrição da aliança entre os Yawanawa (Pano) e uma igreja urbana do Santo Daime, sob orientação do Dr. Cesar Gordon. Bolsista Capes. E-mail: ligiaplatero@ gmail.com.
} 
Lígia Duque Platero - Hegemonia e os programas de educação indígena no México e no Brasil...

emphasize the participation of bilingual cultural promoters as cultural intermediaries between indigenous institutions and communities. In the case of Brazil, teachers were non-indigenous, and their influence was more restricted.

KEYWORDS: History of the Indians; Indigenous policy; Indigenous school education; Indian Protection Service; National Indian Institute.

\section{Introdução}

Nestas notas, compilo informações e reflexões da pesquisa de mestrado realizada no Programa de Pós-Graduação em Estudos Latinoamericanos na Universidade Nacional Autônoma do México (UNAM). O tema dessa pesquisa foi a formação da hegemonia dos Estados nacionais entre os povos indígenas no México e no Brasil por meio da ação de instituições indigenistas e missões religiosas aliadas no período entre 1940 e 1970. Em Platero (2012), abordo a questão da participação dos programas de educação indígena das agências indigenistas Instituto Nacional Indigenista (INI), do México, e Serviço de Proteção ao Índio (SPI) e Fundação Nacional do Índio (FUNAI), do Brasil, no processo de formação da hegemonia ${ }^{3}$ do Estado ampliado entre os povos indígenas nesses países no período destacado.

Trabalhei com a hipótese de que os programas de educação indígena do INI, no México, e do SPI e da FUNAI, no Brasil, foram utilizados para negociar valores e comportamentos tidos como nacionais nas comunidades indígenas. Tais negociações foram parte de uma estratégia política, cultural e econômica, uma vez que a ideia de pertencimento à

\footnotetext{
${ }^{3}$ Aqui, utilizo os conceitos de hegemonia e de Estado ampliado derivados do ponto de vista teórico de Antônio Gramsci (1999[1975]). Para o intelectual italiano, o Estado somente pode ser compreendido como Estado ampliado: uma relação de forças e soma orgânica da Sociedade Política (conjunto de instituições políticas, administrativas e repressivas) e da Sociedade Civil (indivíduos e grupos sociais atuantes e portadores da hegemonia civil, como escolas, jornais, igrejas e missões religiosas). Segundo Gramsci, a hegemonia é um processo de formação da direção política do Estado ampliado, uma estratégia política de dominação que se estabelece a partir de processos de coerção e formação de consenso. De acordo com Lincoln Secco (2006: 43), no marxismo contemporâneo, "hegemonia é geralmente entendida como capacidade que uma classe, uma fração ou conjunto de frações de classe, um grupo social ou até um partido tem para dirigir outros segmentos sociais e, eventualmente, oprimir ou liquidar aqueles que não aceitam pacificamente sua direção. Se entende muitas vezes uma classe que é hegemônica e também dominante, aquela que conduz toda a sociedade". Nestas notas, abordo a questão da formação da hegemonia de uma maneira geral e abrangente.
} 
nação estava ao serviço de uma classe ou conjunto de classes que buscavam levar o "desenvolvimento" às comunidades indígenas. Ainda nessa pesquisa (PLATERO, 2012), abordei a questão da influência de antropólogos (como Gonzalo Aguirre Beltrán, no México, e Darcy Ribeiro, no Brasil) e de missões religiosas (principalmente o Summer Institute of Linguistics) no processo de formação da hegemonia do Estado nacional entre os povos indígenas.

Apresento, inicialmente, uma cronologia dos programas de educação indígena dessas agências indigenistas, no México e no Brasil, entre 1940 e 1970, a título de comparação geral, sendo esse período considerado de auge do indigenismo de integração na América Latina (MEDINA HERNÁNDEZ, 2007). Entretanto, ao longo do texto, destaco particularidades na periodização da política indigenista de cada país. Este texto foi baseado em uma discussão da bibliografia sobre o assunto, na crítica de documentos históricos do SPI encontrados no arquivo do Museu do Índio, no Rio de Janeiro, e na análise de documentos do INI encontrados no arquivo do Consejo Nacional para el Desarrollo de los Pueblos Indígenas (CDI), na Cidade do México.

Concordo com Casas Mendoza (2005) ao afirmar que as ideias de desenvolvimento e nacionalização foram motivadoras para a realização das políticas indigenistas no Brasil e no México no período entre 1940 e 1970. O projeto de "desenvolver", "nacionalizar" e "modernizar" os povos indígenas se expressou nas escolas das instituições indigenistas do INI e do SPI. Como afirma Lima (1992), as escolas do SPI buscaram transformar os povos indígenas em trabalhadores rurais nacionais, modernos e produtivos. Foi perceptível essa mesma motivação nas escolas do INI mexicano. Identifiquei que, nas escolas de ambas as instituições indigenistas, o ensino da língua nacional foi o principal ponto curricular nesse período, como parte dos projetos de modernização, nacionalização e mestiçagem da infância indígena.

No México, o primeiro ciclo do indigenismo mexicano se relacionou com o projeto político de nação proveniente da Revolução Mexicana (1910 - 1917) e com as políticas do secretário de educação José Vasconcelos e a Escola Rural Indígena, na década de 1920. Esse projeto visava à incorporação da população rural indígena à civilização. A Escola Rural era um tipo de escola mambembe, que levava os professores 
"missionários" aos recônditos do país, com seus livros da civilização ocidental e com o propósito de ensinar às populações rurais e indígenas a língua nacional por meio do método direto. Esse método era utilizado para a alfabetização nas escolas públicas mexicanas sem a mediação da língua indígena. Ainda nesse ciclo do indigenismo, a educação socialista no período de Lazaro Cárdenas (1936 - 1940) continuou esse tipo de educação escolar indígena.

Já no segundo ciclo do indigenismo mexicano, destaca-se a atuação do Instituto Nacional Indigenista (INI) a partir de 1948, sob influência da Antropologia e da Linguística Aplicada. A educação indígena proposta pelo INI e seus antropólogos possuía como ponto central do currículo a alfabetização através do método bilíngue, formulado com a participação dos protestantes linguistas do Summer Institute of Linguistcs (SIL), ainda no governo de Lázaro Cárdenas. Uma característica importante do programa de educação indígena do $\mathrm{INI}$ - e que foi fundamental no processo de formação da hegemonia do Estado ampliado nas comunidades - foi a criação da figura do promotor cultural bilíngue, indígena escolhido pelos antropólogos dirigentes dos Centros Coordenadores Indigenistas para estabelecer as negociações dos projetos de desenvolvimento e dos modos de vida entre a instituição indigenista e as comunidades (HERNÁNDEZ, 1999).

Já no caso do Brasil, os programas de educação indígena do SPI foram realizados de forma pragmática, seguindo as influências positivistas e desenvolvimentistas dos militares do SPI, que buscavam "civilizar" os povos indígenas de acordo com as possibilidades de cada Posto Indígena. Nas escolas do SPI, ensinava-se principalmente a língua nacional, através do método direto, e também trabalhos manuais e agrícolas. Entretanto, a prática educativa nas escolas do SPI, em muitos casos, foi reduzida ao ensino da língua nacional, através da qual se ensinavam valores produtivos e nacionalistas.

A título de conclusão preliminar, concordo em parte com Oliveira Filho (1988) ao afirmar que as políticas indigenistas promoveram um processo de interiorização de instituições colonialistas entre as sociedades indígenas, como o caso das figuras dos capitães e dos professores(as) do SPI. Entretanto, a interiorização dessas instituições foi 
realizada de maneira negociada, e sua apropriação se efetivou de acordo com as interpretações nativas sobre o outro 4 .

Cheguei a conclusões similares ao abordar o caso mexicano, quando tratei sobre os promotores culturais bilíngues. Percebi também a importância do ensino da língua nacional, nesses dois países, para o convencimento dos povos indígenas sobre a adoção de hábitos modernos e nacionais, e destaquei a participação de missões religiosas nesse processo.

\section{O caso mexicano}

Como antecedentes do período entre 1940 e 1970, destaco primeiramente aspectos do chamado primeiro ciclo da política indigenista de educação no México, compreendido entre as décadas de 1920 e 1940. O projeto de formação do Estado nacional, surgido a partir das lutas políticas da Revolução Mexicana, continha uma ideologia nacionalista e revolucionária. Segundo essa ideologia, os povos indígenas "isolados" em suas comunidades deveriam ser incorporados à nação mexicana através de políticas de mestiçagem. ${ }^{5}$

A Antropologia mexicana nasceu em meio a esse ideário político da Revolução, associado aos estudos antropológicos e às políticas de transformação social. Desde 1917, Manuel Gamio, à frente da Direção de Estudos Arqueológicos e Etnográficos do governo revolucionário, iniciou pesquisas e projetos para criar uma mudança cultural induzida entre as populações indígenas. A pesquisa etnográfica coordenada por ele no Vale de Teotihuacán foi a experiência piloto da fundação de um novo conceito de pesquisa antropológica. Assim, a Antropologia aplicada e o

\footnotetext{
${ }^{4}$ Penso que este tipo de pesquisa, que assume o ponto de vista dos brancos e das políticas de Estado, associase mais a uma Antropologia do Estado e pode vir a ter um diálogo frutífero com os estudos etnográficos que trazem à tona propriamente a história indígena e suas diferentes historicidades e formas de perceber o tempo, a mudança de suas relações com os não indígenas e suas instituições. Do ponto de vista dos povos indígenas, suas relações com os brancos e com a sociedade nacional podem estar relacionadas com a vivência de mitos e com a reprodução ou transformação de estruturas (SAHLINIS, 1981; GORDON, 2006; VILAÇA, 2006).

${ }^{5}$ Esse ideal de nação mestiça já existia desde o período pós-independência, no qual liberais e conservadores buscaram redimir o "atraso indígena", colocando em prática políticas que visavam a mestiçagem por meio da educação, do ensino do espanhol, da assistência médica e da incorporação da mão de obra indígena (LANDA, 2011). Nesse sentido, os atores sociais da Revolução mexicana deram uma nova roupagem ao projeto liberal de mestiçagem do século XIX.
} 
indigenismo continham a ideologia do mesmo projeto de poder e de nação. Pensava-se que o etnólogo poderia se infiltrar entre os índios e realmente conhecê-los para alcançar a sua assimilação à nação, e a educação passou a ser vista como a principal forma de nacionalizar e civilizar as populações indígenas. Esse tipo de Antropologia tinha um sentido prático de aplicação imediata ao meio indígena (LANDA, 2011).

Entre 1921 e 1924, o intelectual José Vasconcelos foi secretário da educação e, nesse período, formulou o projeto das Escolas Rurais, que buscava a castelhanização dos povos indígenas por meio do chamado "método direto de ensino", como parte do projeto nacionalista mexicano. Ele considerou que não era necessário o conhecimento das diferenças etno-culturais dos povos indígenas para realizar o projeto de sua incorporação à nação. Vasconcelos deu início ao trabalho dos professores missionários como uma forma de civilizar a população com um grande esforço pedagógico. Esses professores missionários atuavam nas áreas mais distantes, promovendo a educação rural e indígena. Esse plano atuava por meio das escolas ambulantes, planejada para atuar em curtos períodos de tempo em cada localidade (LANDA, 2011).

Entre 1925 e 1928, o intelectual Moisés Sáenz foi secretário de educação da SEP e, em 1932, trabalhou na Estação Experimental de Incorporação do Índio, em Carapan (Michoacán), onde desenvolveu uma pesquisa etnográfica para descobrir as limitações do programa educativo implantado nas Escolas Rurais da Secretaria de Educação Pública (SEP), sob comando de José Vasconcelos. Depois da experiência de Carapan, em 1932, Moisés Sáenz propôs um projeto de desenvolvimento comunitário para povos indígenas que respeitasse, ao menos em teoria, as particularidades culturais de cada povo. Esse projeto deveria envolver conhecimentos científicos das áreas de Pedagogia, Linguística, Medicina, Educação, Higiene, Agronomia, Economia e Etnologia, visando ao desenvolvimento social e a incorporação dos indígenas à nação (PLATERO, 2012).

Sáenz concluiu que a chamada "incorporação do índio", que foi o objetivo da Escola Rural, tentava fazer com que os índios negassem a si mesmos, sendo absorvidos pela civilização ocidental. Sáenz considerava necessário integrar o México a partir de uma fusão entre a cultura indígena e a ocidental, em um projeto original de nação. Para ele, a cultura 
indígena era considerada parte da nacionalidade, e não sua negação (LANDA, 2011 ).

Outro período fundamental desse primeiro ciclo do indigenismo, que visava à "incorporação" dos povos indígenas à nação e a formação de uma nação mestiça, foi durante o governo de Lázaro Cárdenas (19361940), com as Escolas Rurais e a chamada "educação socialista". Segundo Lerner (1979), esse tipo de educação foi produto do regime cardenista e sua negociação com as massas populares. Entretanto, foi herdeira dos ideais contidos no terceiro artigo da Constituição de 1917, que previa uma educação laica e antirreligiosa.

O projeto de educação socialista deu continuidade às Escolas Rurais em meio indígena, visando à incorporação dos indígenas à nação. Segundo Kay Vaughan (2001[1997]), os professores federais se tornaram atores explicitamente políticos no governo Cárdenas, ajudando na formação das confederações nacionais camponesas e sindicais que, em 1938, foram incorporadas por Cárdenas ao partido oficial, chamado nesse momento de Partido da Revolução Mexicana (PRM).

A educação socialista ocorreu de maneira simultânea à campanha de laicização do Estado, com o fechamento de templos, a nacionalização dos bens do clero e o fechamento de colégios religiosos. De acordo com Lerner (1979, p. 32), a educação socialista foi, em parte, uma escola contra o clero católico, luta essa que tinha começado nos primeiros anos do cardenismo. O ponto alto do conflito entre Estado e igreja católica no México havia ocorrido na Guerra Cristera (1926 - 1929), mas o conflito continuava no período Cárdenas. Devido a esses conflitos entre governos revolucionários e igreja Católica, o governo cardenista passou a ter mais simpatia pelos missionários protestantes.

Nesse contexto de crise política, Moisés Sáenz foi para a Guatemala e conheceu o missionário protestante estadunidense William Cameron Townsend. Sáenz simpatizou com o trabalho de alfabetização bilíngue que o missionário realizava entre os indígenas cakchiqueles. O propósito de Townsend era ensinar o Novo Testamento para os povos indígenas em sua própria língua. Mas o que interessava a Sáenz era a eficiência do método para o ensino do espanhol. Sáenz considerou esse método de alfabetização bilíngue uma oportunidade para integrar os indígenas à nação sem prejudicar as línguas e as culturas nativas, visando, assim, a 
colocar em prática o seu projeto de integração dos povos indígenas à nação.

Em seu retorno ao México, Sáenz participou da aproximação entre o governo de Cárdenas e os missionários protestantes estadunidenses do Summer Institute of Linguistics (SIL), que foram considerados por Todd (2006) como missionários do Estado no México. Com a criação do SIL, em 1936, esse instituto auxiliou o governo mexicano na criação de alfabetos nas línguas indígenas e cartilhas bilíngues para os povos indígenas do México.

A interação de intelectuais mexicanos e estadunidenses na década de 1930 e, principalmente, as relações estabelecidas entre os mexicanos Manuel Gamio e Moisés Sáenz e o estadunidense John Collier (antropólogo que participou da formulação do Indian New Deal para os EUA) foram parte do processo que levou à realização do Congresso de Pátzcuaro, em Michoacán, em 1940, e à criação do Instituto Indigenista Interamericano (III), em 1941 (BLANCHETTE, 2006). A criação do III, na Cidade do México, tornou-se uma referência para a política indigenista nas Américas, com o estímulo à criação dos Institutos Indigenistas Nacionais nos países membros e a difusão do indigenismo de integração.

Entretanto, após a morte de Moisés Sáenz, em 1941, e com as transformações das relações entre México e EUA associadas à Segunda Guerra Mundial, percebe-se uma ruptura na política indigenista no México, que passou a preocupar-se mais intensamente com as demandas desenvolvimentistas e da transformação dos hábitos dos povos indígenas por meio da Ciência Aplicada. Assim, iniciou-se uma segunda fase do indigenismo no México, fase essa que dava mais ênfase às políticas de desenvolvimento entre os povos indígenas, que se intensificou com a criação do Instituto Nacional Indigenista em 1948.

\section{Política indigenista e Ciência Aplicada}

A partir do estabelecimento, em 1942, da aliança entre México e EUA na Segunda Guerra Mundial, a aproximação entre esses países levou o estímulo à Ciência Aplicada no México, disciplina que passou a ser a base da política indigenista de integração. Durante o governo Ávila 
Camacho (1940 - 1946), foram amplificadas as propostas de desenvolvimento comunitário dos povos indígenas.

Nesse governo, a política indigenista foi posta em prática pelo Departamento de Assuntos Indígenas (DAI) e pela Secretaria de Educação Pública (SEP), associadas a instituições de caráter científico, como o Instituto Indigenista Interamericano, a Escola Nacional de Antropologia e História (ENAH), criada no mesmo ano de 1942, e a agência de missionários linguistas Summer Institute of Linguistics (SIL). Nesse período, os discursos dos cientistas e do presidente estavam em sintonia: a ciência estava ao serviço do desenvolvimento das comunidades indígenas. Ambos afirmavam que era necessário ter conhecimentos sobre a diversidade cultural da população indígena para que os programas econômicos, sanitários e educativos fossem mais efetivos.

Nesse governo, o Departamento de Assuntos Indígenas (DAI), criado em 1936, ampliou os seus planos de levar o desenvolvimento para as comunidades indígenas através dos Centros de Capacitação Econômica (BELTRÁN, 1973). Em relação à SEP, essa secretaria lançou um programa de educação indígena como consequência da Lei de Emergência da Campanha Nacional de Alfabetização, em 1943, quando Jaime Torres Bodet era Secretário de Educação. Buscava-se alfabetizar as massas indígenas através do projeto de alfabetização bilíngue de civilização (III, 1944, p. 294).

Já no governo Miguel Alemán (1946 - 1952), o projeto nacional desenvolvimentista de unificação nacional repercutiu profundamente na política indigenista. Durante esse governo, o paradigma de desenvolvimento comunitário que existiu durante o governo Ávila Camacho foi substituído pela ideia de desenvolvimento regional. A experiência do Vale do Tennessee nos EUA (Tennessee Valley Authority) possibilitou a aparição do conceito teórico de desenvolvimento regional, que foi utilizado como exemplo para o México.

Durante o governo de Alemán, os projetos de construção de grandes represas em diversas regiões da República, como o Projeto da Cuenca de Tepalcatepec, em Michoacán, e o Projeto da Cuenca de Papaloapan, em Oaxaca, resultaram no deslocamento e no reacomodo de vários povos indígenas, como foi o caso dos mazatecos e chinantecos de Oaxaca. Esses projetos tinham como objetivo a criação de hidrelétricas e 
a realização de trabalhos de desenvolvimento agrícola, educacional e de saúde junto às comunidades, além da criação de estradas e a construção de povoados (SECRETARIA DE RECURSOS HIDRÁULICOS, 1947).

A existência, desde 1947, dos projetos de desenvolvimento nas áreas indígenas permitiu que o arqueólogo Alfonso Caso, um dos chamados "caudilhos culturais" da Revolução Mexicana, utilizasse a sua influência política para gerar um projeto que resultou na criação do Instituto Nacional Indigenista (INI), em 1948. A desaparição do Departamento de Assuntos Indígenas (DAl) e a extinção de escolas especiais para indígenas durante o governo de Miguel Alemán foram elementos importantes, que abriram a possibilidade para a criação do Instituto (BELTRÁN, 1973).

Como órgão autônomo, o INI articulava diversas secretarias. O seu trabalho buscava desenvolver integralmente as regiões consideradas isoladas e culturalmente atrasadas pelo governo. A proposta do INI de desenvolvimento regional e de integração posta em prática nos Centros Coordenadores Indigenistas $(\mathrm{CCl})$ foi inspirada nas propostas do indigenismo interamericano, mas ganhou um caráter diferenciado devido à influência da Antropologia e da Linguística Aplicada.

Um grande número de antropólogos e linguistas formados na Escola Nacional de Antropologia e História (ENAH) fizeram parte do INI, como Alfonso Villa Rojas, Julio de la Fuente e Alejandro Marroquín, sob a liderança de Gonzalo Aguirre Beltrán6 (Medina Hernández, 2007). O projeto do INI de integração recebeu muita influência política e ideológica desse último antropólogo, o qual argumentava que a "aculturação" dos povos indígenas era uma forma de se atingir a cidadania (BELTRÁN, 1973). Esse antropólogo participou como diretor do primeiro Centro Coordenador Indigenista, criado em 1951 em Chiapas, entre os tzotziles e tzeltales, o qual se tornou referência para todos os outros Centros Coordenadores.

Os Centros Coordenadores deveriam coordenar as ações de diversas secretarias de governo (Educação Pública; Agricultura e Pecuária; Saúde; Comunicações e Obras Públicas) para o desenvolvimento das

\footnotetext{
${ }^{6}$ Gonzalo Aguirre Beltrán foi um importante intelectual orgânico do indigenismo mexicano, tendo assumido vários cargos da burocracia indigenista. Foi diretor do Instituto Indigenista Interamericano (III) entre 1964 e 1970, e assumiu simultaneamente a direção do INI e da Subdiretoria de Cultura Popular e Educação Extraescolar de educação indígena da SEP entre 1970 e 1976, depois da morte de Alfonso Caso.
} 
regiões indígenas, realizando diversas ações, que iam muito além das ações educativas da Secretaria de Educação Pública (SEP). Entre 1948 e 1970, o INI criou 12 Centros Coordenadores7, burocratizando as regiões indígenas. No projeto oficial do INI, a função dos $\mathrm{CCl}$ era principalmente o estímulo econômico, obtido através da construção de infraestrutura, de caminhos e estradas, a dotação de créditos, a ação sanitária e a educação. Segundo o discurso dessa instituição, a educação tinha um destaque privilegiado, pois era considerada "um cimento sólido do desenvolvimento" (INI, 1964, p. 23).

No programa de educação indígena do INI, enfatizava-se a alfabetização em línguas indígenas com a utilização do método bilíngue de transição (das línguas indígenas para o espanhol) e com o auxílio das cartilhas bilíngues produzidas pelos missionários do SIL. No projeto do INI, os professores e professoras deveriam ser bilíngues e precisavam conhecer as particularidades culturais de cada povo indígena para negociar e introduzir costumes associados ao desenvolvimento econômico nas comunidades. Esse tipo de educação foi chamado por Júlio de la Fuente (chefe da comissão técnica consultiva) de "educação intercultural" e por Gonzalo Aguirre Beltrán de "educação democrática" (DE LA FUENTE, 1973 [1964]).

A figura dos promotores culturais foi criada porque os indigenistas detectaram que havia resistência das comunidades indígenas em relação à escola. A presença de professores (homens) que não pertenciam às comunidades indígenas e que geralmente desconheciam a língua nativa resultou em uma baixa frequência escolar, principalmente das meninas, que eram proibidas de frequentar a escola por suas famílias.

Aguirre Beltrán foi responsável por criar a figura dos promotores culturais bilíngues, que eram os professores das escolas dos Centros Coordenadores. Eles eram escolhidos por serem bilíngues e líderes comunitários. Para a contratação como promotores culturais, os

\footnotetext{
${ }^{7}$ O CCI tzeltal-tzotzil (1951) em Chiapas, com 46 escolas em 1952; o CCI da Tarahumara em Chihuahua (1952), com 30 escolas em 1953; o CCI de Papaloapan (1954) em Temazcal, Oaxaca, que em 1955 congregava 23 escolas; o CCI da Mixteca Baixa (1954), em Oaxaca, que tinha 7 escolas em 1955; o CCI da Mixteca Alta (1954), também em Oaxaca, que em 1958 tinha 47 escolas; o CCI de Yucatán (1959), entre os mayas; o CCI da Mazateca Alta (1959), em Huautla de Jimenez, que tinha 14 escolas em 1961; o CCI dos coras e nahuas (1960), em Nayarit; o CCI de Tlapa (1963), dos mixtecos e tlapanecos, em Guerrero; o CCI de Cherán (1964), dos purépechas, em Michoacán; o CCI de Zacapoaxtla (1968), entre os nahuas e totonacos, em Puebla; e o CCI de San Luís de la Paz (1969), entre os chichimecas, em Guanajuato (INI, 1964 e CASAS MENDOZA, 2005, p. 94).
} 
antropólogos procuravam pessoas da comunidade com algum status e respeitabilidade e que, de preferência, soubessem o espanhol (INI, 1964). Sua função, além de alfabetizar por meio do método bilíngue, era negociar com as comunidades os projetos de desenvolvimento do governo.

Os promotores culturais bilíngues foram os principais intermediários culturais que levaram a cabo as políticas de instauração de um projeto cívico nacional nas comunidades. Eles podem ser considerados agentes de formação da hegemonia, porque, além de participarem ativamente do processo de "civilização" e colonização do imaginário da infância indígena nas escolas, adquiriram grande poder de negociação nas comunidades, levando os projetos de mestiçagem cultural para dentro e fora das escolas.

De acordo com o ex-professor Otílio Vásquez, os promotores culturais geralmente eram homens. Seu trabalho nas comunidades era muito duro, já que, muitas vezes, tinham que viver em comunidades que não eram as suas e precisavam negociar com comerciantes e, inclusive, com invasores dos ejidos (entrevista com professor Otílio Vásquez na Cidade de Oaxaca, em oito de abril de 2011).

Os promotores culturais bilíngues do INI tiveram uma participação contraditória no processo de formação da hegemonia do Estado ampliado nas comunidades. Por um lado, trabalharam para a burocracia estatal e foram aliados do governo, participando do "processo civilizatório" e levando modos de vida e costumes da sociedade nacional para as comunidades. Por outro, transformaram-se em líderes comunitários, associados às lutas pela posse da terra. Por meio da atuação dos promotores, pudemos perceber que estruturas burocráticas e coloniais do INI passaram a interagir e a fazer parte das estruturas de poder propriamente indígenas.

A escola do INI deveria ser um centro difusor do projeto cívico nacional dessa instituição indigenista em toda a comunidade, sendo um centro organizador de festas e celebrações cívicas. A castelhanização por meio do método bilíngue de transição foi o principal ponto curricular nas escolas dos CCl. Buscava-se concluir a alfabetização na língua indígena nos dois primeiros anos de escolarização e, nos anos seguintes, a educação era realizada somente em espanhol, ou utilizando a língua 
indígena somente para explicar palavras do espanhol que não eram compreendidas pelos alunos.

Além da castelhanização pelo método bilíngue de transição, os promotores bilíngues do INI também davam aulas de aritmética, geografia elementar (para ensinar o conceito de "território nacional"), história pátria elementar, esportes (principalmente vôlei e basquete) e instrução sanitária. Buscavam, também, combater o alcoolismo e as práticas médicas tradicionais, chamadas pelos indigenistas do INI de "superstições" (INI, 1964, p. 47). Uma estratégia de educação informal utilizada nos $\mathrm{CCl}$ era o teatro gigñol, uma prática educativa realizada pelos promotores culturais bilíngues para convencer as populações indígenas a aceitar as campanhas agrícolas, educativas e sanitárias do INI (INI, 1964, p. 48).

\section{Institucionalização da educação bilíngue de transição}

Em 1952, o total de escolas coordenadas pelo INI era 46. Em 1963, esse número já tinha chegado a 237, indicando um movimento de expansão dos Centros Coordenadores e das escolas bilíngues (INI, 1964). 1963 foi um ano significativo para a política indigenista no México, devido ao convênio entre o trabalho do INI e o trabalho da Secretaria de Educação Pública (SEP), que até aquele momento aconteciam de forma separada. Nesse ano, a SEP ratificou a educação bilíngue como meta educativa para os povos indígenas e contratou promotores culturais bilíngues qualificados (HEATH, 1972).

A entrada dos promotores culturais do INI na SEP e no Sindicato Nacional de Trabalhadores de Educação (SNTE) amplificou o caráter político das ações dos promotores culturais e professores bilíngues nas comunidades e a nível nacional (HERNÁNDEZ, 1999). Os promotores culturais e os professores bilíngues ampliaram sua participação na negociação, persuasão e coerção para a realização dos projetos de desenvolvimento nas comunidades.

Assim, os Centros Coordenadores do INI e a SEP passaram a se apoiar mutuamente nos programas de educação indígena, com a intenção de realizar o desenvolvimento regional ou a transformação social dirigida, 
proposta pela Antropologia Aplicada. Segundo Bello Domínguez (2007, p. 42), em 1968, o INI e a SEP operavam em 25 regiões indígenas, com 2150 promotores culturais. Em 1970, havia 3.815 docentes, entre promotores e professores bilíngues, que atendiam em 1.601 escolas. Assim, nesse segundo ciclo do indigenismo mexicano do século $X X$, 0 desenvolvimento regional e a educação indígena bilíngue acabaram se tornando também um paradigma da Secretaria de Educação Pública.

\section{Crise do indigenismo de integração}

No final da década de 1960 e início da década de 1970, antropólogos europeus e americanos realizaram duras críticas ao indigenismo de integração. Estas foram qualificadas como "políticas etnocidas" no Simpósio sobre a Fricção Interétnica na América do Sul, em Barbados, entre os dias 25 e 30 de janeiro de 1971, com o apoio do Conselho Mundial de Igrejas. Esses antropólogos produziram o documento Declaração de Barbados pela liberação do indígena. Essa declaração foi assinada por diversos antropólogos, entre eles Miguel Alberto Bartolomé, Guillermo Bonfil Batalla e Darcy Ribeiro. Este documento afirmava que os povos indígenas continuavam sujeitos a relações coloniais nas sociedades nacionais latino-americanas e denunciava as políticas indigenistas como políticas etnocidas (MORA e HERNÁNDEZ, 1986, p. 520).

A partir de então, no México, houve uma polarização entre os antropólogos que seguiam defendendo as ações indigenistas do INI e os antropólogos que as denunciavam como etnocidas. Um dos principais antropólogos a propor um tipo de Antropologia Crítica foi Guillermo Bonfil Batalla (1970, p. 54), que propôs em seu texto Del indigenismo de la revolución a la Antropología Crítica o compromisso dos antropólogos com a defesa de uma sociedade multiétnica. $\mathrm{O}$ autor passou a defender a autonomia dos povos indígenas como novo paradigma nas lutas por direitos. Essa ruptura a nível discursivo não significou a supressão das políticas indigenistas de integração a partir de 1970. Pelo contrário, nessa década, houve no México um incremento da política indigenista, que se expandiu através da SEP e do INI em função de um aumento significativo 
do número de Centros Coordenadores. Entre 1971 e 1978, foram criados $71 \mathrm{CCl}$ na República (INI, 1978, p. 389).

Com a criação da Direção Geral de Educação Extraescolar em Meio Indígena (DGEEMI) da SEP, Aguirre Beltrán tornou-se Subsecretário de Educação da SEP e Diretor do INI (NAHMAD, 1978, p. 232). Esse antropólogo estava entre os que defendiam o indigenismo de integração e afirmava que a política indigenista mexicana do INI estava realizando a "empresa improrrogável de modernização da vida rural nas regiões interculturais de refúgio" (BELTRÁN, 1973, p. 270). Por causa dos diversos programas de educação indígena do INI e da Direção Geral de Educação, a partir de 1971, aumentou consideravelmente o número de alunos e alunas indígenas e de professores e professoras bilíngues (DOMÍNGUEZ, 2007). Estes seguiram com uma crescente influência política nas comunidades indígenas, sendo peças-chave no processo de formação da hegemonia do Estado ampliado nas comunidades indígenas no México.

\section{O caso brasileiro}

Desde 1940, o Serviço de Proteção aos Índios (SPI) teve uma expansão sem precedentes, com um aumento significativo no número de pacificações e com a criação de Postos Indígenas, de acordo com a política expansionista de Getúlio Vargas chamada "marcha para o Oeste".

Em 1939, o governo de Getúlio Vargas editou o decreto lei n. 1794, que estabelecia a criação do Conselho Nacional de Proteção aos Índios (CNPI). Esse órgão (que possuía representantes indigenistas e antropólogos) foi criado devido à influência do indigenismo interamericano e deveria orientar a realização da política indigenista brasileira. Entretanto, o único delegado brasileiro no Congresso de Pátzcuaro, Edgard Roquette Pinto, considerou o projeto de criação do Instituto Indigenista Interamericano (III) contrário aos interesses brasileiros (BLANCHETTE, 2006).

O SPI não se filiou ao III naquele momento - a política indigenista brasileira seguia com a influência principal das ideias positivistas, e a política indigenista seguia enfatizando a transformação dos povos indígenas em trabalhadores nacionais (LIMA, 1992). Nos Postos Indígenas 
do SPI, a figura dos indígenas chamados de "capitães" foi fundamental para a persuasão e coerção que levava à realização dos projetos do SPI, instituindo a autoridade do órgão indigenista nas sociedades indígenas.

Os capitães, no Brasil, e os promotores culturais bilíngues, no México, podem ser identificados como os principais intermediários culturais, ou "negociadores", entre os povos indígenas e as agências indigenistas. Entretanto, além de se envolverem com questões associadas ao desenvolvimento, os promotores também estavam diretamente envolvidos com os programas de educação indígena no México. Enquanto isso, no Brasil, os capitães estavam envolvidos apenas com assuntos administrativos e produtivos.

Os Postos Indígenas do SPI eram considerados um centro educativo e de civilização. $\mathrm{O}$ ensino do português, de valores produtivos, cívicos e nacionalistas deveria ser realizado cotidianamente, dentro e fora das escolas. E era considerado imprescindível para que se colocasse em prática o projeto de integração e de formação de uma identidade nacional mestiça entre os povos indígenas.

\section{As escolas do SPI}

Desde 1940, o SPI aumentou o número de edifícios associados à política indigenista, tais como escolas, enfermarias, prédios administrativos e residências (SPI, 1942, p. 1). Assim, a burocratização das regiões indígenas se ampliou. No início dos anos 1940, dos 94 Postos Indígenas que o SPI mantinha ativos, 40 pertenciam ao modelo de Nacionalização e Educação, enquanto 24 foram Postos Indígenas de Atração (PIA). Exceto nos PIA e nos Postos Indígenas de Criação, em todos os outros PI indicados pelo SPI havia a presença de um auxiliar de educação (MENDOZA, 2005, p. 12).

Entre 1940 e 1967, as escolas do Serviço de Proteção ao Índio seguiram o modelo das Escolas Rurais dos Estados da Federação. O SPI criava normas e projetos para as escolas dos Postos Indígenas de Nacionalização e Educação (SPI, 1942 e 1943a). Entretanto, as escolas eram fragmentadas e acabaram seguindo as vicissitudes e o pragmatismo dos chefes e funcionários de cada Posto Indígena (LIMA, 1992). O discurso 
oficial do SPI afirmava que os PI deveriam ter uma função educativa também para os adultos: deveriam ter educação cívica e profissional, além de levar aos povos indígenas métodos mais apropriados de trabalho (SPI, 1942, p. 3).

A partir da análise dos Boletins Internos do SPI de 1942 e 1943, observei que as principais diretrizes do SPI para as escolas dos PI no período eram: 1) a alfabetização em português, através do método direto; 2) o ensino de valores cívicos, com atividades de culto à bandeira e canto de hinos; 3 ) o ensino de trabalhos manuais (diferenciados por sexo), com a intenção de garantir o ensino do trabalho agrícola; 4) ensino de hábitos de higiene e 5) matemática elementar (SPI, 1942 e 1943). De acordo com o relatório do SPI de 1942:

O que chamamos educação dos índios consiste em: a) dar-Ihe a ideia de Pátria e o seu culto cívico, cerimônias em torno à bandeira, hinos, História do Brasil através dos fatos mais culminantes, etc.; b) alfabetização dos menores e adultos de ambos os sexos; c) ensinos de trabalhos manuais e domésticos; d) prática agrícola e pecuária; e) limpeza e higiene (SPI, 1943, p. 13).

Esse plano do SPI buscava criar, nessas escolas, um microcosmo do que deveria ser a nação. Durante toda a década de 1940, houve uma preocupação por parte das inspetorias regionais do SPI de controlar a frequência escolar utilizando o recurso burocrático dos avisos mensais, buscando aumentar a assistência escolar (SPI,1942, p. 15). Visando a esse objetivo, o SPI passou a recomendar o oferecimento de comidas para alunos e alunas, de preferência produzidos no mesmo PI, estimulando também a produção de alimentos nos Postos.

Como observado no discurso oficial, o ensino da língua nacional nas escolas do SPI era considerado o principal instrumento para a aculturação e a integração da infância indígena:

Começam a aprender nossa língua e, com ela, uma série de noções que pouco a pouco modificam completamente sua concepção das coisas. Vão adotando novos processos de produção, novos hábitos alimentícios e novas necessidades que os levam a modificar sua vestimenta, a forma da casa e da aldeia e, por fim, a 
constituição de sua própria família (MINISTÉRIO DA AGRICULTURA, 1953, p. 4).

Quando Gama Malcher foi diretor do SPI, essa instituição fez uma autocrítica da educação indígena que vinha realizando nos Postos. Em 1953, o SPI afirmava que existiam 66 escolas indígenas nos PI, e todas eram essencialmente idênticas às escolas rurais do Brasil, "utilizando os mesmos métodos e inclusive o mesmo material didático, evidentemente inadequado para os indígenas" (SPI, 1953, p. 10).

Essas escolas tinham como objetivo principal a alfabetização. Em algumas delas, existia também o ensino de técnicas de trabalho, como confecção de roupas e trabalhos de agulhas para meninas e habilidades artesanais para meninos (SPI, 1953, p. 10). Assim, observa-se que essas escolas tinham o objetivo de negociar os valores da infância indígena e "incorporá-los" à nação, com ensinos que visavam à geração de trabalhadores sedentários e nacionais, da mesma forma como observou Lima (1992).

Com a criação da Seção de Estudos (SE), em 1947, o SPI passou a realizar pesquisas linguísticas e antropológicas que, no entanto, não tinham um caráter aplicado. Durante a administração de Gama Malcher (1950 - 1954), a SE buscou substituir as ideias positivistas do SPI por uma orientação científica, com base nas Ciências Sociais e, principalmente, na Antropologia. A partir de 1952, Darcy Ribeiro passou a ser chefe da SE do SPI, ampliando o quadro de antropólogos da instituição. Entretanto, essa postura não conseguiu transformar de maneira profunda a prática nos $\mathrm{PI}$ (ROCHA, 2003).

Quando Darcy Ribeiro foi diretor da SE, ele realizou uma autocrítica em relação à educação realizada nos $\mathrm{PI}$, criticando também o ensino monolíngue de português, principalmente para povos indígenas "pouco aculturados". Devido a isso, a SE propôs, em 1953, um programa de reestruturação das escolas, que se associava ao projeto de aproximar as práticas do SPI ao indigenismo interamericano ${ }^{8}$.

\footnotetext{
${ }^{8}$ Em 23 de julho de 1953, o Congresso Nacional aprovou a entrada do Brasil no Instituto Indigenista Interamericano, quando esse órgão era membro da Organização dos Estados Americanos (OEA). Em 1954, o SPI participou pela primeira vez de maneira oficial do Congresso Indigenista Interamericano. O diretor José Maria da Gama Malcher foi o presidente da delegação, e seus assessores foram Roberto Cardoso de Oliveira e o técnico de educação Lincoln Allison Pope. No ano de 1954, o SPI se aproximou de órgãos internacionais, como a OIT e a UNESCO (MINISTÉRIO DA AGRICULTURA, 1955).
} 
De acordo com Casas Mendoza (2005, p. 159), Darcy Ribeiro acreditava na necessidade de implantação da educação bilíngue de transição no país, conforme o modelo de ensino interamericano. Entretanto, afirmava que esse tipo de ensino era impossível no país devido ao grande número de povos indígenas existentes e ao baixo orçamento do SPI.

A proposta educativa de Darcy Ribeiro se chamava Casa do Índio e foi posta em prática no PI Getúlio Vargas, entre os Carajás, na Ilha do Bananal. Este foi considerado um posto modelo, em uma região de forte expansão da fronteira agrícola. Essa escola buscava adaptar o currículo que centralizava o ensino da língua nacional e de trabalhos manuais às especificidades dos Carajás. Nela, pretendia-se ensinar português oral sem sotaque, práticas higiênicas e técnicas de trabalho artesanal (MINISTÉRIO DA AGRICULTURA, 1955, p. IV).

Darcy Ribeiro chegou à conclusão de que a alfabetização dos povos indígenas somente oferecia vantagens no processo de integração em casos de povos indígenas que já estavam "assimilados". Ensinar o português oral era uma tentativa de ampliar a efetividade do ensino e da "integração". De acordo com o relatório de 1953, estava sendo preparada, nesse mesmo ano, uma cartilha especial para essa escola, com temas considerados de interesse pelos Carajás (MINISTÉRIO DA AGRICULTURA, 1953). A escola Casa do Índio deveria ter o edifício escolar com o formato das casas tradicionais Carajás. Em um dos seus salões, deveriam ser instaladas máquinas para trabalhos manuais para o uso dos adultos, visando ao desenvolvimento econômico e a chamada emancipação dos Postos (MINISTÉRIO DA AGRICULTURA, 1953).

Quando Darcy Ribeiro trabalhou como chefe da SE, ele chegou a defender a cooperação entre o SPI e as missões religiosas (católicas e protestantes) para levar a cabo a política indigenista, devido à carência de recursos financeiros do SPI. Entretanto, esse antropólogo demonstrou preferir a atuação de missões protestantes junto aos povos indígenas, pois essas ingressavam no país com recursos financeiros próprios e não disputavam com o SPI os recursos para a política indigenista (MINISTÉRIO DA AGRICULTURA, 1953). A mais influente das missões católicas que já realizara assistência aos povos indígenas era a Salesiana (que disputava recursos financeiros com o Estado). 
Muitas missões religiosas protestantes ingressaram no país para realizar assistência junto aos povos indígenas desde a década de 1940 (ROCHA, 2003). Essas missões protestantes realizaram as primeiras experiências de educação indígena utilizando o método bilíngue de transição, com a intenção de ensinar o Evangelho nas línguas indígenas - muitas delas com o apoio da protestante Summer Institute of Linguistics (SIL). ${ }^{9}$

Darcy Ribeiro chegou a apoiar a ideia da entrada de missões protestantes estrangeiras para o Brasil. O antropólogo sabia que o SPI não teria recursos para atender a todas as populações indígenas do país que necessitavam da assistência do SPI (SPI, 1953). Além disso, os missionários protestantes possuíam seus próprios recursos financeiros, e muitos possuíam conhecimentos em Linguística e interesse na criação de alfabetos nas línguas indígenas, com o objetivo de fazer a tradução da Bíblia. Já os católicos, desde a década de 1930, competiam com o SPI por financiamento público e geralmente educavam por meio do método direto usado nas escolas brasileiras (SPI, 1953).

Quando Darcy Ribeiro saiu do SPI e ingressou no Ministério da Educação, em 1955, a proposta educativa Casa do Índio foi abandonada. A partir de 1957, com a entrada do coronel José Luiz Guedes como diretor do SPI, o ideário evolucionista e positivista do SPI foi resgatado, e a proposta de educação agrícola rural formou parte das iniciativas desenvolvimentistas do período.

No Programa Educativo Indígena, proposto em 1959, a prioridade absoluta do currículo era a alfabetização da língua nacional e o ensino prático de trabalhos agrícolas utilizando ferramentas modernas para o plantio de hortas e pomares. O ensino de higiene e festividades cívicas também tinha destaque no currículo (MINISTÉRIO DA AGRICULTURA, 1959, p. 38).

Principalmente a partir do golpe militar de 1964, o caráter desenvolvimentista do SPI se acentuou, aumentando as características empresariais dos $\mathrm{PI}$, que deveriam se tornar autossuficientes para gerar

\footnotetext{
${ }^{9}$ Em 1956, o SIL chegou a ingressar no país através de um convênio com o Museu Nacional, para que os missionários protestantes realizassem pesquisas sobre as línguas indígenas de maneira acadêmica, sem o prévio acordo de que trabalhassem na área da educação. Entretanto, mesmo assim essa missão religiosa começou a criar cartilhas para o ensino bilíngue de transição para alguns povos indígenas (SUMMER INSTITUTE OF LINGUISTICS, 1960).
} 
recursos para o sustento da máquina burocrática da agência indigenista. A partir do golpe militar, a doutrina de segurança nacional do Exército também influenciou a política indigenista, principalmente em áreas de fronteira, conformando o trinômio Força Aérea Brasileira (FAB)/ missões religiosas/povos indígenas (HECK, 1996, p. 75). Desde então, foi dada continuidade à proposta de educação agrícola, que somente foi questionada a partir de 1967, em um período de crise do SPI, devido às acusações de genocídio, corrupção e ineficiência contra essa instituição divulgadas nos meios de comunicação (ROCHA, 2003).

Em 1967, abriu-se uma investigação judicial para julgar as acusações ao SPI. Ao final desse ano, o SPI e o Conselho Nacional de Proteção aos Índios (CNPI) foram desativados e foi criada a Fundação Nacional do Índio (FUNAI). As acusações de corrupção, somadas à influência do III e da OEA na política brasileira da década, levaram à realização de profundas transformações político-jurídicas dos órgãos estatais indigenistas (HECK, 1996).

Com a formação da FUNAI, o programa de educação indígena dessa agência indigenista se aproximou das propostas do III - principalmente em 1969, quando a FUNAl realizou um convênio com a missão protestante do Summer Institute of Linguistics. Essse convênio resultou na criação da primeira escola de ensino bilíngue de transição em um PI, em 1970. Entretanto, de acordo com Pinheiro da Cunha (1990), essa metodologia para a alfabetização e a contratação de professores indígenas pela FUNAI somente foi regulamentada nas escolas a partir de 1972, com a lei n. 75, de seis de agosto de 1972.

Com a aliança entre a FUNAl e o indigenismo interamericano, os técnicos indigenistas brasileiros participaram de encontros organizados pelo III e, inclusive, o governo brasileiro patrocinou o VII Congresso Indigenista Interamericano, realizado em Brasília entre os 7 e 11 de agosto de 1972. Apesar das críticas ao indigenismo de integração no final da década de 1960 e da adequação do governo brasileiro aos discursos do III aceitos internacionalmente, as escolas da FUNAl continuaram desempenhando um papel importante no projeto de "integração" dos povos indígenas à economia de mercado. E seguiram com a proposta de promoção de uma educação básica para os indígenas se integrarem progressivamente à sociedade nacional (FILHO e FREIRE, 2006, p. 131). 
Conclusões finais: processos diferenciados de formação da hegemonia

A formação da hegemonia do Estado nacional e suas relações com a prática educativa governamental é um problema histórico que faz parte dos projetos de nação de grande parte dos países latino-americanos. Esse é um problema que permanece até o tempo presente. No Brasil e no México, entre 1940 e 1970, as escolas primárias do INI e do SPI tiveram um objetivo de mestiçar a infância indígena, ensinando hábitos e modos de vida da sociedade nacional, principalmente por meio do ensino da língua nacional. Entretanto, em ambos os países, houve diversas fases e matizes em meio a esse processo.

No Brasil, na década de 1940, o SPI buscou primeiramente civilizar e transformar a infância indígena em futuros trabalhadores e trabalhadoras nacionais, através das escolas nacionais dos Postos Indígenas. Na década de 1950, surgiu um novo projeto educativo, com a Casa do Índio de Darcy Ribeiro, influenciado pelo indigenismo interamericano. $\mathrm{O}$ antropólogo visava à integração dos povos indígenas à nação, mas buscando preservar algumas de suas características culturais. Esse antropólogo também foi influenciado pelo indigenismo interamericano em relação ao gosto pelo método de educação bilíngue dos missionários protestantes.

Com a saída de Darcy Ribeiro do SPI em 1955 e com o retorno dos coronéis para a diretoria do SPI a partir de 1957, o ideário evolucionista e positivista do SPI foi resgatado, e a proposta de educação agrícola rural formou parte das iniciativas desenvolvimentistas do período. Na década de 1960, instaurou-se o desenvolvimentismo no SPI e na FUNAl, e a educação dos povos indígenas também teve esse caráter associado ao ensino de técnicas agrícolas, além do tradicional ensino do português. Somente a partir de 1972 a FUNAl incorporou o método de educação bilíngue que existia no México e em vários países latino-americanos adeptos do Instituto Indigenista Interamericano. 
No caso específico do México, desenvolveu-se, nesse período, o segundo ciclo do indigenismo mexicano do século $X X^{10}$. Nesse segundo ciclo, o enfoque foi dado à Antropologia Aplicada e aos paradigmas de integração e desenvolvimento das regiões indígenas por meio das práticas do INI nos Centros Coordenadores, criadas por antropólogos ligados à instituição. Buscava-se manter as distinções culturais dos diferentes povos indígenas nesse processo de integração à nação, ainda que essas distinções fossem transformadas em folclore. O INI buscou focar-se no método bilíngue de transição das línguas indígenas para o espanhol em seus programas de educação. No caso mexicano, a influência protestante do Summer Institute of Linguistcs no meio indígena foi muito grande devido à permissão dada pelo governo mexicano para a formulação das cartilhas bilíngues.

O ensino nas escolas das instituições indigenistas no Brasil e no México, entre 1940 e 1970, buscou negociar os modos de vida tradicionais dos povos indígenas como parte de processos de formação de consenso sobre o pertencimento à nação considerada mestiça. $O$ ensino da língua nacional e de trabalhos manuais nas escolas do INI e do SPI foi utilizado para colonizar o imaginário da infância indígena, levando hábitos considerados produtivos e nacionais às comunidades com o intuito de gerar desenvolvimento.

Entretanto, no Brasil, a escolarização teve uma influência mais limitada no processo de formação da hegemonia, porque os professores e professoras eram não indígenas e, em geral, não tinham grande atuação política nas reservas, sendo essa função de intermediários culturais relegada ao cargo de capitão. Já no México, os promotores culturais bilíngues, além de atuarem nas salas de aula, também tinham a função de negociar a implantação de projetos de desenvolvimento do Instituto Nacional Indigenista.

A participação de indígenas nos processos de negociação como intermediários culturais entre os povos indígenas e as agências indigenistas é uma problemática comum para a maioria dos países do subcontinente. A análise comparada da atuação desses agentes pode

\footnotetext{
${ }^{10}$ No primeiro ciclo, o enfoque foi conferido à Escola Rural e às missões culturais desenvolvidas por José Vasconcelos por meio da Secretaria de Educação Pública. Tinha-se como objetivo o paradigma de incorporação dos indígenas à nação por meio do método direto de alfabetização.
} 
auxiliar na compreensão dos processos de colonialidade dos povos indígenas, que persistem até a atualidade nos países latino-americanos, bem como repensar estratégias político-administrativas que visem a romper com essa colonialidade.

\section{Referências bibliográficas}

\section{México}

AGUIRRE BELTRÁN, G. Teoría y práctica de la educación indígena. México: SEP, 1973.

BAEZ LANDA, Mariano. Indigenismo y antropología: experiencia disciplinar y práctica social. México: Universidad Veracruzana, 2011.

BELLO DOMINGUEZ, J. Educación y pueblos excluidos. México: UNAM/Miguel Ángel Porrúa, 2007.

BONFIL BATALLA, G. Del indigenismo de la revolución a la Antropología Crítica. In: De eso que llaman Antropología Mexicana. México, DF: Editorial Nuestro Tiempo, 1970. p. 39-65.

DE LA FUENTE, J. Educación, antropología y desarrollo en la comunidad. México: Colección SEP-INI 4, 1973 [1964].

GARCÍA MORA, C., MEDINA HERNÁNDEZ, A. (Org.). La quiebra política de la antropología social en México: II. La polarización (1971 - 1976). México: UNAM, 1986.

HEATH, S. B. La política del lenguaje en México, de la colonia a la nación. México: Instituto Nacional Indigenista, 1972.

KAY VAUGHAN, Mary. La política cultural en la Revolución: Maestros, Campesinos y escuelas en México, 1930 - 1940. México: Fondo de Cultura Económica, 2001.

LERNER, Victoria. La Educación Socialista: Colección Historia de la Revolución Mexicana - Periodo 1934 - 1940. México: COLMEX, 1979.

MEDINA HERNÁNDEZ, A. La educación indígena en México: una reflexión etnográfica (Anuario 1988). Tuxtla Gutiérrez: Centro de Estudios Superiores de México y Centroamérica de la Universidad Ciencias y Artes de Chiapas, 1999.

Los ciclos del indigenismo en México: la política del indigenismo del siglo XX.

In: TARRIO GARCIA, M.; COMBONI SALINAS, S.; DIEGO QUINTANA, R. (Org.). 
Mundialización y diversidad cultural. México: UAM/ HDSC Publicaciones, 2007. p. 113-132.

NAHMAD SITTON, Salomon. La educación bilingüe y bicultural para las regiones interculturales de México: revisión crítica. México: INI, 1978.

TODD, Hartch. Missionaries of the State: The Summer Institute of Linguistics, State Formation and Indigenous México, 1935 - 1985. Tuscaloosa: The University of Alabama Press, 2006.

\section{Brasil}

BLANCHETTE, T. G. Cidadãos e Selvagens: Antropologia Aplicada e Administração Indígena nos Estados Unidos, 1880 - 1940. 2006. 552 f. Tese (Doutorado em Antropologia) - Programa de Pós-Graduação em Antropologia da Universidade Federal Rio de Janeiro (UFRJ), [2006].

CASAS MENDOZA, C. A. Nos olhos do outro: nacionalismo, agências indigenistas, educação e desenvolvimento Brasil-México (1940 - 1970). 2005. 317 f. Tese (Doutorado em Ciências Sociais) - Programa de Pós-Graduação em Ciências Sociais da Universidade de São Paulo (USP), [2005].

CUNHA, L. O. P. A política indigenista no Brasil: as escolas mantidas pela FUNAI. 1990. 129 f. Dissertação (Mestrado em Antropologia) - Programa de Pós-Graduação em Antropologia da Universidade de Brasília (UnB), [1990].

GORDON, Cesar. Economia Selvagem: ritual e mercadoria entre os índios XikrinMebêngôkre. São Paulo: Editora UNESP/ISA; Rio de Janeiro: NUTI, 2006.

HECK, E. D. Os índios e a caserna: políticas indigenistas dos governos militares - 1964 a 1985. 1996. 137 f. Dissertação (Mestrado em Antropologia) - Programa de PósGraduação em Antropologia da Universidade Estadual de Campinas (UNICAMP), [1996].

LIMA, Antônio Carlos de Souza. Um grande cerco de paz: poder tutelar e indianidade no Brasil. 1992. 256 f. Tese (Doutorado em Antropologia) - Programa de Pós-Graduação em Antropologia da Universidade Federal do Rio de Janeiro (UFRJ), [1992].

Poder tutelar e formação do Estado no Brasil: notas a partir da criação do Serviço de Proteção dos índios e Localização de Trabalhadores nacionais. Revista Desacatos, Cidade do México, n. 33, p. 53-66, 2010.

OLIVEIRA FILHO, João Pacheco. O nosso governo: os Ticuna e o regime tutelar. São Paulo [Brasília]: Marco Zero/CNP, 1998. 
- ¿Una etnología dos indios misturados?: identidades étnicas y territorialización en el Nordeste de Brasil. Revista Desacatos, Cidade do México, n. 33, p. 13-32, 2010.

OLIVEIRA FILHO, J. P.; ROCHA FREIRE, C. A. A presença indígena na formação do Brasil. Brasília: UNESCO/SECAD, 2006.

PLATERO, Lígia D. Política indigenista y hegemonía en Brasil y México: los programas de educación indígena en el período 1940 y 1970. 2012. Dissertação (Mestradoe, estudos Latino-americanos) - Programa de Pós-Graduação em Estudos Latino-americanos da Universidade Nacional Autônoma do México (UNAM), [2012].

ROCHA, L. M. A política indigenista no Brasil: 1930 - 1967. Goiânia: Ed. UFG, 2003.

SAHLINS, Marshal. Metáforas históricas e realidades míticas: estrutura nos primórdios da história do reino das ilhas Sandwish. Rio de Janeiro: Zahar Editores, 1981.

SECCO, L. Gramsci e a Revolução. São Paulo: Alameda, 2006.

VILAÇA, Aparecida. Cristãos sem fé: alguns aspectos da conversão dos Wari (Pakaa Nova). In: WRIGHT, Robin M. (Org.). Transformando os deuses: os múltiplos sentidos da conversão entre os povos indígenas no Brasil. Campinas: Editora Unicamp, 1999. p. 109-137.

UFRJ, 2006.

Quem somos nós: os wari encontram com os brancos. Rio de Janeiro: Editora

\section{Referências gerais}

GRAMSCI, A. Cuadernos de la cárcel. México: Ediciones Era/ Benemérita Universidad Autónoma de Puebla (edición crítica del Instituto Gramsci, 6 tomos), 1999 [1975].

\section{Documentos}

III. La alfabetización de las masas en México. Boletín Indigenista, vol. IV, n.01, 1944, pág. 294.

INI. Memorias, realidades y Proyectos. México: INI, 1964.

MINISTÉRIO DA AGRICULTURA. Relatório de 1953 - SPI. Rio de Janeiro: Museu do Índio/FUNAI, 1953.

Relatório de atividades do SPI durante o ano de 1954 - SPI. Rio de Janeiro: Museu do Índio/FUNAI, 1955.

. Relatório de atividades do Serviço de Proteção aos Índios. Rio de Janeiro: Museu do Índio/FUNAI, 1959. 
SECRETARÍA DE RECURSOS HIDRÁULICOS. Acuerdo por el cual se dispone la creación de la Comisión de Tepalcatepec, n. 15, tomo CLXIII, 17 de julio de 1947.

SPI - SERVIÇO DE PROTEÇÃO AO ÍNDIO. Boletim Interno. 2-13. Rio de Janeiro: Museu do Índio/FUNAI, 1942.

Boletim Interno. 14-17. Rio de Janeiro: Museu do Índio/ FUNAI, 1943 a.

Relatório de 1942. 1-38. Rio de Janeiro: Museu do Índio/FUNAI, 1943 b.

SUMMER INSTITUTE OF LINGUISTICS. Relatório das atividades dos membros do "Summer Institute of Linguistics" entre os índios brasileiros no ano de 1959, dirigido ao diretor do Serviço de Proteção aos Índios. Rio de Janeiro: Museu do Índio/FUNAI. Microfilme 338, fotograma 881 - 893, 1960.

\section{Entrevista}

OTILIO VÁZQUEZ. Ex-professor zapoteco e diretor de CCI. Cidade de Oaxaca, oito de abril de 2011. 